\title{
STUDENT PERCEPTIONS AND USE OF AN INVENTORY TO FACILITATE LEARNING OF INDIVIDUAL TEAM-EFFECTIVENESS
}

\author{
Patricia Kristine Sheridan, Doug Reeve, and Greg Evans \\ Institute for Leadership Education in Engineering, and Department of Chemical Engineering and Applied Chemistry \\ Faculty of Applied Science and Engineering, University of Toronto \\ patricia.sheridan@utoronto.ca,doug.reeve@utoronto.ca,greg.evans@utoronto.ca
}

\section{INTRODUCTION}

Team-based projects have become a common method of modeling real-world experience and meeting required graduate attributes in engineering. In these projects, much of a student's grade is attributed to work produced by an entire team, creating a need for instruction on how to work effectively as team members in addition to course-content instruction. A web-based tool is in development to create a virtual environment in which students can learn about and improve their individual team-effectiveness competencies through self- and peer-assessments. Framed as a guided reflection, these assessments are facilitated using an inventory which identifies 18 competencies along three aspects of team-effectiveness: Organisational, Relational and Communication competencies [1]. The inventory assesses observable behaviours that translate to specific levels of competency so as to provide a foundation for normalized self- and peer-assessments, as well as provide examples of how to improve.

A study to assess student perceptions and use of the inventory was conducted in the Fall 2012 term in two upper year courses. The first course was a third-year course on energy systems that is required of all students in the Energy Option of Engineering Science and the second a fourth-year engineering leadership course which any engineering student can select as an elective. The objective of this study was to determine if students in a required engineering course perceived and used the inventory differently than those who self-selected into an engineering leadership course.

\section{METHODOLOGY}

Before providing assessments, the students were given a lecture on individual team-effectiveness behaviours and how to work together effectively. In week 7 of a 13-week term, students were asked to provide selfand peer-assessments on their effectiveness as team members. Self- and anonymized peer-assessments were provided to students as feedback on their individual teameffectiveness, with three competencies identified as their strengths and three as their greatest opportunities for improvement. After submitting their last deliverable for their team projects (around week 12) students provided assessments for a second time, and similarly received feedback based on these assessments.

Students were required to complete the assessments for course purposes but were given the option to consent to their assessments being used as part of this research study. Students who consented to participate in the research study were asked to complete two additional surveys, one at the beginning of the course outlining their beliefs around individual team-effectiveness, and one at the end on their perception and use of the inventory. Consent rates were high in both courses at $94 \%$ for the energy policy course, and $77 \%$ for the leadership course.

\section{PRELIMINARY FINDINGS}

Preliminary findings from the surveys indicated that students in both courses found the feedback to be useful. Both indicated that, on average, they received feedback structured in an understandable and positively phrased manner. Students in the energy systems course provided, on average, lower second-round assessments as compared to the leadership course which provided lower first-round assessments. Students in both courses, however, provided similar assessments - no significant difference in mean or standard deviation. Students in the leadership course were better able to describe the learning they gained from their team experience, and according to the data, were able to improve team-level as well as individual-level teamwork skills. Students in the energy systems course had less to say about how they used the inventory.

Preliminary findings indicate that students in the selfselected leadership course perceive the use of the inventory to be more beneficial to their team experience than those in the required engineering course.

\section{Acknowledgements}

This work was supported by the Higher Education Quality Council of Ontario, the Dorothy and William Palm Queen Elizabeth II Graduate Scholarship in Science and Technology, and the University of Toronto Open Fellowship Fund.

\section{References}

[1] P. K. Sheridan, L. El Gammal, J. Phillips, G. Evans, and D. Reeve, "A Team-effectiveness Inventory for Guided Reflection and Feedback," American Society of Engineering Education Annual Conference and Exposition, Atlanta, Georgia, 2013. 